\title{
Mother Tongue Interference in English Writing among Tamil School Students
}

\author{
Prashana Nair Kumaran ${ }^{a}$ \\ kshananair@gmail.com \\ Centre for Research in Language and Linguistics, \\ Universiti Kebangsaan Malaysia, Malaysia \\ Pramela Krish ${ }^{b}$ \\ pramela@ukm.edu.my \\ Centre for Research in Language and Linguistics, \\ Universiti Kebangsaan Malaysia, Malaysia
}

\begin{abstract}
Writing is considered one of the most challenging language skills that students need to acquire. In Malaysia's vernacular schools, students encounter several challenges as they need to write in variety of languages: their mother tongue, Malay and English. The students' mother tongue can interfere when writing in English due to the difference of structures between these languages. This paper aims to explore this issue further by examining how the Tamil language in particular influences its young native speakers' writing of English essays. For the purpose of this study, 30 writing samples of Year 5 students from a Tamil school were studied in terms of structure, vocabulary usage, and spelling. Errors committed in the essays were identified, categorized and scrutinized. The findings reveal that the main issues in the students' writings are related to grammar, direct translation of the Tamil language, vocabulary and spelling. While we need to understand why and how mother tongue interference affects their writing, it is crucial to curb these writing issues at the primary school level so that such errors can be minimized as they will be doing higher levels of writing. The findings of the study suggest that students need to recognise the differences between their first language (L1) and the English language and learn to understand the different features and structures of the languages in order to write communicative and correct sentences.
\end{abstract}

Keywords: Writing challenges; English; mother tongue interference; interlanguage errors; Tamil schools

\section{INTRODUCTION}

Mastery of a second language (L2) necessitates the ability to use the language appropriately and strategically. This includes displaying a certain degree of structural accuracy and communicative potential while writing in the language (Dar \& Khan, 2015). Language learners however regard writing as one of the greatest challenges in L2 learning (Fareed et al., 2016). Writing skills, unlike speaking skills, cannot be developed simply by being in a specific environment or through the observation of others (Darus \& Khor, 2009; Satariyan et al., 2018). The underlying cognitive processes are complex and many factors can potentially affect one's writing ability. These factors can be psychological, linguistic, pedagogical or cognitive (Haider, 2012; Hyland, 2003). However, students mostly encounter difficulties with the structural components of the English language because the poorly chosen structures complicate the textual content (Fareed et al., 2016).

${ }^{a}$ Main author

${ }^{b}$ Coressponding author 
Malaysian children begin learning English formally in preschool at the young age of five to six. It is a compulsory subject in the national curricula, i.e., the Standard Curriculum for Primary Schools (KSSR) and the Standard Curriculum for Secondary Schools (KSSM). The children are taught the English language at the primary level (7 to 12 years of age) and the secondary level (13 to 17 years of age). The students therefore undergo 11 years of formal learning of English in addition to sitting for examinations at the school and national levels.

Despite the exposure, some students still face difficulties in mastering the language upon completing secondary school (Azman, 2012; Manan \& Raslee, 2017). This is a common problem among students from both the national and the vernacular schools. The national schools use Malay, the national language, as the main medium of instruction and English is taught as an L2. There are two vernacular schools in Malaysia, Tamil and Chinese vernacular schools. Tamil is the main medium of instruction in the former, whereas Mandarin is the main medium in the latter. Unlike in the national schools where English is taught as the L2, English is taught as a third language (L3) in the vernacular schools. The vernacular school students learn their first language or mother tongue and Malay as their L2 (Nazri \& Azmi, 2013). Another difference between the national and vernacular schools is the time allocated for English instruction. Based on the KSSR, English instruction is allocated 300 minutes per week in the national schools, but only 150 minutes per week in Tamil schools.

According to a report by Maju Institute of Educational Development (2020), Tamil school students faced several difficulties in the learning of English, particularly in writing. These students find it challenging to grasp three different languages throughout their six years of schooling at the primary level (Maniam, 2010; Raman, 2007). Tamil school students are multilingual learners who need to undergo the complex process of learning three languages (Azmi et al., 2016). This complex process was illustrated by Cummins (1984) who argued that when learning an L2, some of what was originally learned through the LI does not have to be relearned in the L2. Although some surface features of each of the languages are distinct, according to Cummins, L1 and L2 are intrinsically connected. L2 learners may be able to transfer what they already know from the LI into the L2. Similarly, when learning an L3, transfer from the L1 and the L2 may occur. Such transfer can be 'positive', facilitating learning of a target language (TL). Transfer, however, can also be negative, interfering with the learning of the TL. This will be discussed in the next section.

\section{L1 INTERFERENCE IN THE LEARNING OF L2}

A language learner relies extensively on their L1 when learning a new language (Lado, 1957). When attempting to speak in the TL, for instance, the learner would transfer the forms and meanings of the L1 to the TL. This transfer is not restricted to TL production but would also take place when the learner is trying to understand the TL. Transfer is also assumed as the main contributor to the ease and difficulty in learning the structure of the TL (Lado, 1957). Lado suggested that learners will learn structures that are similar in both languages easily but will find different structures more difficult. It was argued that when transfer takes place, L1 structures that are similar with the TL structures will function well in the TL. In contrast, L1 structures that are different from the TL structures will not function as well and ought to be changed.

As mentioned previously, transfer can be either positive or negative. Positive and negative transfers, respectively, refer to whether a transfer results in something correct or incorrect (Gass, Behney \& Plonsky, 2020). Positive transfer or facilitation takes place when relevant units or structures of both languages are the same and results in the correct production of the TL. Negative transfer, also known as interference, takes place when different units or structures of both languages interfere in the learning of the TL. The temporary difficulties that 
a bilingual child have in keeping both languages apart is also referred to as an interference (Alsaigh \& Kennison, 2017).

Weinreich (1953) defined language interference as the deviation from the norms of either language of a bilingual, which occurs in speech. This happens as a result of their familiarity with more than one language. The interference implies the rearrangement of language patterns that results from the introduction of foreign elements into the more highly structured domains of language, such as the bulk of the phonemic system, a large part of the morphology and syntax, and some areas of vocabulary. According to Dulay et al. (1982), due to habits formed in L1, language interference could also occur as an automatic transfer of the L1 surface structure to the surface structure of the TL.

\section{TAMIL INTERFERENCE IN ENGLISH WRITING}

L1 structures may transfer to TL structures during TL writing. Past research has shown that in most TL writing tasks, Tamil school students tend to transfer the writing knowledge from their L1 into the TL (Kumar et al., 2014; Maniam, 2010). However, it was found that these were mainly negative rather than positive transfers. Language transfers from the mother tongue, also known as L1 interference, could be attributed to several factors, one of which is the transfer of rules, where the learners apply the writing rules of their L1 to their TL. Sentences in the TL can therefore appear as a direct translation from the L1, stemming from the learners' poor TL command (Hanafi, 2014). Another factor is grammatical interference where the TL sentence structures are unintentionally modified to reflect the L1 sentence structures. These will be further elaborated in the following paragraphs.

Interference of Tamil (L1) in English writing, specifically, may occur because the two languages differ in several linguistic aspects such as syntax and morphology. In terms of differences in syntax, the most prominent would be word order. Tamil uses the Subject-ObjectVerb (SOV) word order but English uses the Subject-Verb-Object (SVO) word order (Kumar et al., 2014; Maniam \& Kesevan, 2016). In Tamil, the main verb always appears at the end of the sentence, but in English sentences, it appears between the subject and the object. Therefore, when constructing English language sentences from Tamil, the verbs need to be relocated (Kumar et al., 2014). Figure 1 shows an example of the difference in word order between an English sentence and a translated Tamil sentence. In the Tamil sentence, the verb is relocated to the end.

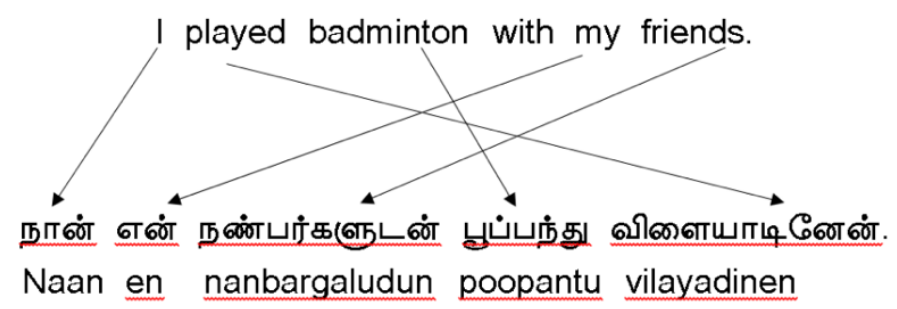

FIGURE 1. Relocation of words when translating an English sentence into Tamil 
The above sentence can also be written in Tamil as,

(i) என் நண்பர்களுடன் நான் பூப்பந்து விளையாடினேன்

[En nanbargaludan naan poopantu vilayadinen]

[My friends and I badminton played], or

(ii) பூப்பந்து விளையாடினேன் நான் என் நண்பர்களுடன்

[Poopantu vilaiyadinen naan en nanbargaludun]

[Badminton played I and my friends], or

(iii) விளையாடினேன் பூப்பந்து நான் என் நண்பர்களுடன்

[Vilaiyadinen poopantu naan en nanbargaludun]

[Played badminton I and my friends].

Although the literal English translations of (i), (ii) and (iii) appear to consist of appropriate vocabulary items and content, the words are incorrectly and awkwardly arranged (Krish \& Oh, 2020). However, though the word order is incorrect in English, they are considered acceptable in Tamil. This is because the word order in Tamil is relatively free and can be flexibly changed without affecting the grammatical meaning of the sentence. Tamil sentences, therefore, exhibit extensive scrambling (word order variation). Hence, the surface permutations of the SOV order are possible with different pragmatic effects. Moreover, in Tamil, not all sentences have subject, verb and object and hence, it is possible to construct valid sentences that have only a verb, or only a subject and object, or without a verb (Maniam, 2010; Sanmuganathan, 2014). These features of Tamil may therefore be transferred when Tamil school students are writing in English.

Next, although Tamil school students also learn tenses in their Tamil language as காலம் [kaalam] இறந்தகாலம் (present), நிகழ்காலம் (past), எதிர்காலம் (future) [iranthakaalam, nigalkaalam, ethirkaalam], it is revealed that English tenses are much more complex and difficult to learn (Kumar et al., 2014). In English, tenses are an essential part that needs to be mastered. Since grammar is related to the construction of correct sentences, the learners must be able to express the sentences in the right form of tenses. Learners' language proficiency is determined by the correct usage of tenses in the sentences (Listia \& Febriyanti, 2020).

Another difference between the two languages is in terms of pronouns. Tamil school students may find it challenging to learn subject-object distinction when using pronouns in English because pronoun subjects and objects are less phonetically distinct than in other languages. Moreover, in English, pronouns are words which take the place of nouns or antecedents and their use renders sentences to be less repetitive and less cumbersome (Hassan \& Sawalmeh, 2013). Common nouns (e.g. "apple" or "girls") can be used as antecedents, but are later replaced by pronouns (e.g. "it" or "they") throughout the ensuing discussion. Such substitution however does not take place in Tamil. Tamil uses the grammatical case system vetrumai urubugal (வேற்றுமை உருபுகள்) and suffixes are added to nouns to produce different cases, therefore marking, among others, the subject and object of a sentence. In Tamil, there are eight case markers available for a word in suffixed forms. These represent the general possible inflections a word can have when they combine with other words in a sentence (Evangeline \& Shyamala, 2019; Selvam et al., 2009). Given these differing structures, Tamil learners of English may therefore find the pronoun system in English difficult. Aggravating this issue is the fact that pronoun agreement in English, as seen in the example above, is very important. The pronoun (e.g. "it" or "they") should agree with the singularity or plurality of its 
antecedent. Furthermore, Tamil school students may find the various categorization of English pronouns complex. The pronouns are divided into several categories: personal, interrogative, demonstrative, relative, indefinite intensive and reflexive pronouns. English pronouns further present four features with their associated values: person (i.e., first, referring to self; second, referring to one' s interlocutor; or third, referring to another party); number (i.e., singular, one person; or plural, many people); case (i.e., subjective, objective, or genitive); and gender (i.e., feminine, masculine, or neuter) (Fitzgerald et al., 2017). Tamil, in contrast, only has three pronouns: (தன்னிலை, முன்னிலை, and படர்கை).

The two languages also have slightly different parts of speech. There are eight parts of speech in English: verbs, nouns, adjectives, pronouns, adverbs, conjunctions, prepositions, and interjections. In Tamil, however, the parts of speech are verbs, nouns, adjectives, pronouns, adverbs, conjunctions, postpositions and exclamations (Ravishankar \& Shriram, 2018). Singh et al. (2017) argued that English L2 learners' insufficient knowledge of grammatical rules and concepts pertaining to the parts of speech in English contributes to their inability to write well in English.

English and Tamil also differ in terms of their morphology. English is morphologically simple but Tamil is morphologically rich (Kumar et al., 2014). Words consist of morphemes, which are the smallest meaningful units in a word. For example, in English, the word "apples" consists of "apple" + "s", where "s" is a plural marker. The word "played" consists of "play" + "ed", where "ed" is a past tense marker. The English language often conveys the relationships between words by adding affixes to the words as in the preceding examples, or by the order of words within the sentence. Tamil, on the other hand, expresses this via morphological variation of the word.

Tamil school students also tend to write English sentences in the manner they normally speak in their L1. Some pronounce English words agglutinating with the vowel sound /a:/. Therefore, when writing, these students make an assertive sentence interrogative by adding 'ah' at the end of the sentence. This occurs because in Tamil, a sentence ending with 'ah' is taken as an interrogative (Maniam, 2010).

Additionaly, Tamil school students with limited English vocabulary tend to resort to English words and phrases using a direct translation method, sometimes even using Malay, the national language (Maniam, 2010). These strategies often lead to poor word choice and structures when writing English sentences. According to Alqahtani (2015), lack of vocabulary knowledge causes ESL learners to use the same words repetitively in their writing, and it hinders their creativity. Therefore, the ESL learners could not give voice to their thoughts because they lack an adequate vocabulary to be used in their writing.

The errors highlighted above may not be unique only to Tamil school students but also to other learners of English. They also make errors in their usage of singular and plural forms and prepositions (Darus \& Subramaniam, 2009) and in the use of prepositions after verbs, adjectives or nouns in expressions (Roslim, 2013). If a second language learner faces difficulties in learning the English language, the state of affairs in Tamil schools could be even worse, since the students need to master three languages at the same time. We therefore believe it is crucial to address the difficulties that these Tamil school students experience when writing in English. Hence, the main objective of the study is to identify the type of errors that Tamil school students committed in English writing. Since plenty of evidence suggest that the students' mother tongue contributes to these difficulties, we examine in what ways does the Tamil language interfere with the students' English writing. 


\section{METHODOLOGY}

This study was carried out in a Tamil school in Pahang, Malaysia. The school was selected based on convenience sampling as three other schools in the state turned down the research request. This is a government-aided primary school situated in an urban area. This case study employed a qualitative approach for data collection and analysis. In determining the sample for this study, one Year 5 class was selected. The class consisted of students with average writing ability. Year 5 pupils were chosen for this study particularly because, at this level, the students had already had a one-year experience in writing narratives (they were formally introduced to writing narratives in Year 4). Years 1, 2 and 3 students were not sampled as they are only exposed to simple sentence constructions in the English language. Year 4 students were not sampled as they were only recently exposed to narrative writing. Additionally, the school did not allow Year 6 students to participate because they would be taking the national exam, the Primary School Achievement Test (UPSR), that year.

\section{DATA COLLECTION AND ANALYSIS}

A total of 30 samples of English essays were collected from 30 Year 5 students. The essay question was set according to the UPSR format and was part of a writing lesson in class. The question involved narrative writing where students were provided a strip of three pictures, to describe an event. In the UPSR English Paper 2 (writing), 25 marks are allocated for this section, and this weightage affects the overall grade for the English paper to a large extent.

By using content analysis, the researchers were able to analyze the presence, meanings, and relationships of certain words, themes, or concepts used in their essays. The common mistakes made by the students were also analyzed. Here, Mayring's (2014) qualitative content analysis method was used to extract codes through explicative analysis and then the codes were summarized to develop categories and subcategories. This method involves an empirical, methodical, controlled analysis of texts without quantification. It was used because it provides a systematic procedure of content analysis and follows the rules of interpretation strictly. In this study, the researchers extracted students' sentences from their respective essays while retaining the meaning, context, and original words where possible (Mayring, 2014). Based on the content analysis method, the researchers were able to list out the common errors made by these students. Two raters were invited to indicate and score the errors found using the standardised UPSR scoring guide for the purpose of validating the data analysis. Both raters confirmed the researchers' analysis. The students' errors are presented and discussed in the following section.

\section{FINDINGS AND DISCUSSION}

Table 1 presents samples of students' writing errors and their classification.

TABLE 1. Sample of writing errors and their classification

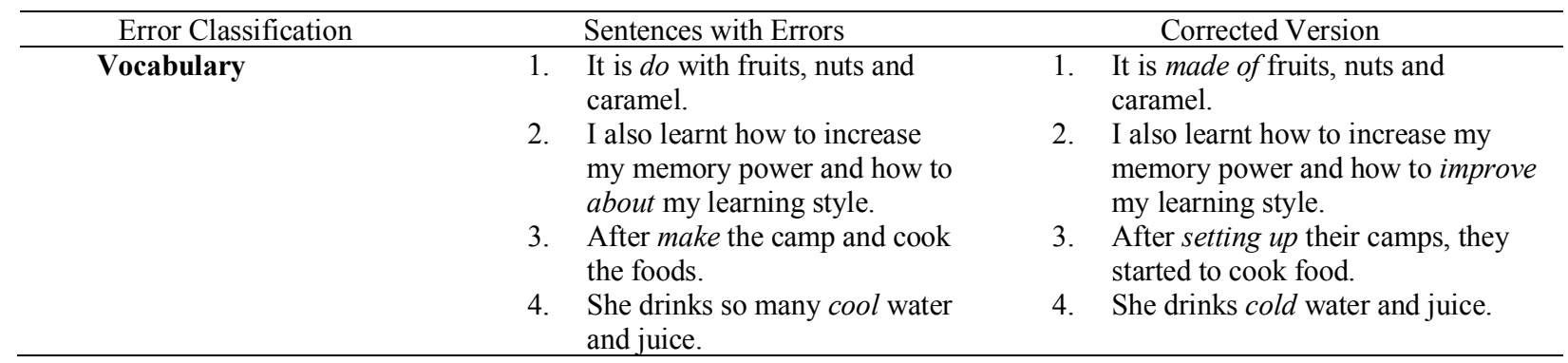




\begin{tabular}{|c|c|c|}
\hline Tenses & $\begin{array}{l}\text { 1. Lastly, we are very hungry. } \\
\text { 2. Last school holiday, Rahul and } \\
\text { his parent visit to Kuala } \\
\text { Lumpur. } \\
\text { 3. He maked a cake. } \\
\text { 4. Mother } \text { cutted the vegetables } \\
\text { for salad. }\end{array}$ & $\begin{array}{l}\text { 1. Lastly, we were very hungry. } \\
\text { 2. Last school holidays, Rahul and his } \\
\text { parents visited Kuala Lumpur. } \\
\text { 3. He made a cake. } \\
\text { 4. Mother } \text { cut the vegetables for salad. }\end{array}$ \\
\hline Word Order & $\begin{array}{l}\text { 1. Siva for the picture he came. } \\
\text { 2. He box open. }\end{array}$ & $\begin{array}{l}\text { 1. Siva came for the picture. } \\
\text { 2. He open the box. }\end{array}$ \\
\hline Subject-Verb Agreement & $\begin{array}{l}\text { 1. He head were bleeding. } \\
\text { 2. After two hours of practice, } \\
\text { they was allowed to go home. }\end{array}$ & $\begin{array}{l}\text { 1. His head was bleeding. } \\
\text { 2. After two hours of practice, they } \\
\text { were allowed to go home. }\end{array}$ \\
\hline Spelling & $\begin{array}{l}\text { 1. They cooked sup in the jungle } \\
\text { 2. We can use energy saving } \\
\text { apaliance. } \\
\text { 3. First, were put tens. } \\
\text { 4. They many thinegs buy there. }\end{array}$ & $\begin{array}{l}\text { 1. They cooked soup in the jungle } \\
\text { 2. We can use energy saving } \\
\text { appliances. } \\
\text { 3. First, we fixed the tents. } \\
\text { 4. They bought many things there. }\end{array}$ \\
\hline Pronouns & $\begin{array}{l}\text { 1. His went to KLCC twin towers. } \\
\text { 2. He mother reminded to wear } \\
\text { helmet. } \\
\text { 3. His mother's reminded wear } \\
\text { the helmet. }\end{array}$ & $\begin{array}{l}\text { 1. They went to KLCC twin towers. } \\
\text { 2. His mother reminded him to wear } \\
\text { his helmet. } \\
\text { 3. His mother reminded him to wear } \\
\text { the helmet. }\end{array}$ \\
\hline
\end{tabular}

In general, the students faced difficulties in writing grammatical sentences in English as they committed errors in the use of the tenses, word order, subject-verb agreement and pronouns. Besides that, these students appeared to have limited English vocabulary and misspelled some words. These findings therefore corroborate past studies that found grammatical and spelling errors as common errors made by L2 learners (Darus \& Khor, 2009; Moe \& Toe, 2020; Singh et al., 2017). The different types of errors are further discussed in the following section.

\section{VOCABULARY}

Some of the errors listed in Table 1 were caused by the students' limited vocabulary, where the students lacked the correct words to express their ideas. According to Alqahtani (2015), having a limited vocabulary repertoire has been acknowledged as the L2 learners' greatest source of problems. We gathered from our analysis that some students did not understand certain words given in the essay question. Hence, those words were incorrectly used in their English sentences. It might also be possible that the students had the tendency to think of what to write in Tamil first before directly translating them into English. This is illustrated in the following extract.

\section{Extract 1. After make the camp and cook the foods.}

"Make" is செய்தல் [seithal] in Tamil and செய்தல் [seithal] is normally used when making reference to any actions. However, this is not the case in English. Camps are usually "set up", and "making" camps are not an ideal word choice. Those who made this error may not have realized the range of vocabulary that English has compared to Tamil when making reference to actions. Their limited vocabulary in English may have led them to think of the appropriate word in Tamil and translated it directly to English.

\section{TENSES}

It is also common for students to use incorrect tenses when writing in English. When asked to write about the past, for instance, some students failed to use the past forms and instead, used the present forms. This is illustrated in the following extracts. 
Extract 2. Lastly, we are very hungry.

Extract 3. Last school holiday, Rahul and his parent visit to Kuala Lumpur.

There were instances whereby students understood the need to use past forms for past events but failed to use its correct form. This is exemplified in the following extracts.

Extract 4. He maked a cake.

Extract 5. Mother cutted the vegetables for salad.

Extracts 4 and 5 demonstrate that the students had added to the base form of the irregular verbs, "make" and "cut", the regular -ed suffix. This is a classic case of overgeneralizing the English past-tense inflection. The students had assumed that all English verbs take the past tense -ed suffix. These errors might have resulted from the students' unawareness of the various rules in using English tenses (Darus \& Subramaniam, 2009). Thus, students have a tendency to get confused with the use of tenses in the English language, although they have studied tenses in the Tamil language.

\section{WORD ORDER}

Another common error made by the Tamil students is associated with word order. This error occurred because unlike English which uses the SVO word order, Tamil uses the SOV word order. Therefore, in Tamil, the verb follows the subject and object. This is exemplified in the following extracts.

Extract 6. Siva for the picture he came.

சிவா படத்திற்காக வந்தான்

[Siva padathirkaage vanthan]

Extract 7. He box open.

நான் பெட்டியை திறப்பேன்

[Naan pettiyai thirappen]

In both extracts, the verb of each of the English sentences, i.e. "came" and "open" was preceded by the subject and object, and therefore was placed at the end. This demonstrates that the Tamil structure, i.e. the SOV word order, has interfered with the English structure. Errors associated with word order are normally products of literal translation of Tamil sentences. The students might have first formulated sentences in Tamil with the SOV order in place before translating them into English literally.

\section{SUBJECT-VERB AGREEMENT}

The students also committed subject-verb agreement errors when writing as demonstrated in the following extracts.

Extract 8. After two hours of practice, they was allowed to go home.

Extract 9. He head were bleeding. 
The plural pronoun "they" in Extract 8 should be followed by the plural form of the "be" verb. On the other hand, the singular subject in Extract 9 should be followed by the singular form of "be". We can also see an error in the use of pronouns being committed in Extract 5. Instead of the possessive pronoun "his", the student wrote "he". This error suggests that this student was aware of the singular noun, but could be unsure that a singular noun should follow a singular verb.

\section{SPELLING}

Spelling errors also occurred rather frequently. Two examples are presented below.

\section{Extract 10.We can use energy saving apaliances.}

Extract 11. They cooked sup in the jungle.

We argue that the above spelling errors could be due to the interference of the students' L2, Malay. Malay learners are normally taught to spell a word syllable by syllable partly because the pronunciation of Malay words normally correspond to their spelling. However, the pronunciation and spelling of English words do not correspond in the same way, and English learners need to know their phonics well in order to spell the words correctly. Often, the students do not master their phonics and tend to spell words incorrectly.

In Extract 11, for instance, the student spelled the word "soup" the way it is spelled in Malay. This is an example of how Tamil school students use their Malay orthographic knowledge to spell out English words (Samuddin \& Krish, 2018). It would appear that their limited orthographic knowledge of English leads them to transfer orthographic knowledge of Malay as a strategy (Figueredo \& Varnhagen, 2006; Wang \& Wen, 2002).

\section{PRONOUNS}

The analysis of the students' essays also indicated that some had difficulty in deciding and distinguishing the use of pronouns in a particular context. Common errors include the use of subjective and possessive pronouns in the subject position and subjective pronouns referring to an antecedent in a sentence. Some examples are discussed below.

\section{Extract 12. His went to KLCC Twin Towers.}

As seen in Extract 12, the student made the error of using the possessive pronoun "his" in the subject position. Based on the picture strip in the essay question, the right pronoun should be "they".

\section{Extract 13. He mother reminded to wear helmet.}

In Extract 13, the student made the error of using the subject pronoun "he", instead of the possessive pronoun "his". Such error resulted from the interference of student's L1, involving the use of pronouns for accurate subject-object distinction. In Tamil, this sentence is written as,

அவன் தாயார் அவனுடைய தலைக்கவசத்தை அணிய நினைவுப்படுத்தினார் [Avan thayaar avanudaiya thalaikavasathai aniya ninaivupaduthinar]. 
As mentioned previously, in Tamil, suffixes are added to nouns to produce different cases, therefore marking the subject and object of a sentence. This is not the case for English. In English, instead of adding suffixes to nouns, subject pronouns (e.g. "he") are used to substitute the noun or antecedent doing the action, whereas object pronouns (e.g. "him") are used to substitute the noun or antecedent affected by the action. This demonstrates that the Tamil structure has interfered with the production of the English structure. Extracts 12 and 13 suggest that the students have some difficulty in using the different types of English pronouns. We argued earlier that English pronouns, with their different types and positions in sentences are much more complex and confusing compared to Tamil pronouns. This might also be exacerbated by the students' lack of practice in terms of using different types of pronouns in their writing (Fitzgerald et al., 2017).

Overall, the analysis has shown that the Tamil school students in this study have indeed made different types of errors when writing English essays. The errors made include grammatical errors such as in the use of tenses, pronouns and violations of word order and subject-verb agreement, and spelling. We also saw that some of these students have poor vocabulary or word choice when writing in English.

Some of these errors, as we argued, can be attributed to the influence of Tamil language structures. We also saw the influence of the students' L2, Malay, in their English essays. However, other factors such as limited knowledge of English structures and lack of practice can also contribute to their poor writing.

\section{PEDAGOGICAL IMPLICATIONS}

The findings from this study point towards some pedagogical implications. Firstly, the challenges faced by Tamil school students in English language writing are a valuable indication of the students' learning progress. These writing samples reveal the real scenario and the problems faced by Tamil school students in writing. Therefore, teachers will be better informed of the kinds of errors made by Tamil school students, and address these errors more specifically, with teaching methods specific to those errors. For example, the findings will be helpful as a reference for the teachers to design lessons that address the differences in L1 and L2 writing knowledge and this can enhance students' writing skills.

Secondly, the findings from this study demonstrate the similarities and differences between the student's TL, L1 and even L2, Malay. These include the contrasting aspects between the grammatical structures and vocabulary of the three languages. Students need to recognise the and learn to understand the different features of these languages in order to write sentences with correct structures. Meanwhile, teachers must emphasise the different structures of grammar and writing, which are dealt with differently in the relevant languages. Hence these findings would educate both teachers and students on the variations of structures of these languages. This would help English language teachers to highlight specific rules in the Tamil and Malay languages which are inappropriate when writing in English.

Additionally, the findings demonstrate that the main factors preventing the students from writing effectively in English were their poor grammatical and vocabulary knowledge in English. Revelations through these findings could clarify and assist teachers in the process of improving students English knowledge in order to help students understand and write better. Additionally, as pointed out earlier by Cummins (1984), students' L1 plays a crucial role in their acquisition of the TL because it can affect their writing in positive or negative ways. The findings from this study will be able to facilitate teachers in helping students to create positive L1 transfers into their L2 by tapping into the errors analysed and addressing them strategically. Kim and Yoon (2014) confirmed that if L2 writers know how to employ their L1 strategically during the writing process, then L1 use could be beneficial to L2 writing. This is because the 
spectrum of L1 usage displayed by students is considered important for them to have ideas for their writing. Being unable to transfer them positively into the L2 may hinder them from voicing the ideas due to limited L2 vocabulary and other related factors (Darmi et al., 2018).

There are several other recommendations, particularly for ESL teachers, policymakers, and future researchers. Asmin (2019) suggested that language teachers should use contextualised teaching strategies to assist students to utilise different strategies. Besides that, there is a need to educate teachers with the knowledge on the effects of L1 interference in order to equip them with the skills and knowledge of addressing this issue while teaching writing. Teachers also could prepare themselves by participating in workshops or webinars concerning L1 interference issues. Such involvement would help assist ESL teachers in Tamil schools in improving their approach in teaching writing.

\section{CONCLUSION}

This study has provided a glimpse of issues faced by Tamil school students when writing in the English language. From the analysis of the findings, this study concludes that the common mistakes were found in five areas: vocabulary, tenses, spelling, subject-verb agreement, and pronouns. It appears that some of the errors made can be attributed to transfer from their L1 and L2. When this occurs, students tend to construct error-ridden sentences as a result of their confusion between the different structures of Tamil, Malay and English. These are interlanguage errors, caused by the students' application of L1 and L2 structures whilst writing or speaking in the English language. Lastly, the findings also suggest that a writing assistance in the form of a writing guide that covers basic grammatical rules and sentence construction may be necessary to help the students write effectively. This type of writing assistance may be useful to clarify Tamil school students' confusion between writing in Tamil and the English language. In particular, a writing assistance in a bilingual form, incorporating both the Tamil language and the English language will be able to assist the Tamil school students in enhancing their writing skills.

\section{REFERENCES}

Alqahtani, M. (2015). The importance of vocabulary in language learning and how to be taught. International Journal of Teaching and Education. 3(3), 21-34. https://doi.org/10.20472/te.2015.3.3.002

Alsaigh, T., \& Kennison, S. M. (2017). Second language interference during first language processing by Arabic-English bilinguals. Frontiers In Psychology Language Science. 8, 1956. https://doi.org/10.3389/fpsyg.2017.01956

Asmin, A. I. (2019). Teachers' strategies in teaching English at vocational high school in Luwu. IDEAS: Journal on English Language Teaching and Learning, Linguistics and Literature. 7(2), 261-267. https://doi.org/10.24256/ideas.v7i2.1040

Azman, H. (2012). Implementation and challenges of English language education reform in malaysian primary schools. 3L: The Southeast Asian Journal of English Language Studies. 22(3), 65-78.

Azmi, M. N. L., Ching, L. T. P., Jamaludin, N., Ramli, M. N. H., Razali, M. H., Amram, M. A. Y. \& Jayakumar, K. (2016). The comparisons and contrasts between English and Malay languages. English Review: Journal of English Education. 4(2), 209-218. https://doi.org/10.25134/erjee.v4i2.335

Cummins, J. (1984). Bilingualism and special education: Issues in assessment and pedagogy. Clevedon: Multilingual Matters.

Dar, M. F. \& Khan, I. (2015). Writing anxiety among public and private sectors Pakistani undergraduate university students. Pakistan Journal of Gender Studies. 10,121-136. 
Darmi, R., Puteh-Behak, F., Abdulllah, H., Darmi, R. \& Wahi, W. (2018). Variations of L1 use in the English language class. GEMA Online ${ }^{\circledR}$ Journal of Language Studies. 18(2), 284-311.

Darus, S. \& Khor, H. C. (2009). Common errors in written English essays of Form One Chinese students : A case study. European Journal of Social Sciences. 10(2), 242-253.

Darus, S. \& Subramaniam, K. (2009). Error analysis of the written English essays of secondary school students in Malaysia : A case study. European Journal of Social Sciences. 8(3), 483-495.

Dulay, H., Burt, M., \& Krashen, S. (1982). Language two. New York: Oxford University Press.

Evangeline, M. M., \& Shyamala, K. (2019). Noun identification for Tamil language using morphophonemic rules. International Journal of Recent Technology and Engineering, 8(4). 11867-11873. https://doi.org/10.35940/ijrte.d9588.118419

Fareed, M., Ashraf, A. \& Bilal, M. (2016). ESL learners' writing skills: Problems, factors and suggestions. Journal of Education \& Social Sciences. 4(2), 81-92. https://doi.org/10.20547/jess0421604201

Figueredo, L. \& Varnhagen, C. K. (2006). Spelling and grammar checkers: Are they intrusive? British Journal of Educational Technology. 37(5), 721-732. https://doi.org/10.1111/j.1467-8535.2006.00562.x

Fitzgerald, C. E., Rispoli, M. \& Hadley, P. A. (2017). Case marking uniformity in developmental pronoun errors. First Language. 37(4), 391-409. https://doi.org/10.1177/0142723717698007

Gass, S., Behney, J., \& Plonsky, L. (2020). Second Language Acquisition An Introductory Course (5th ed.). New York: Routledge. https://doi.org/10.4324/9781315181752

Haider, G. (2012). An insight into difficulties faced by Pakistani student writers: Implications for teaching of writing. Journal of Educational and Social Research. 2(3), 17-28. https://doi.org/10.5901/jesr.2012.v2n3p17

Hanafi, A. (2014). The second language influence on foreign language learners' errors: The Case of the French language for Algerian students learning English as a foreign language. European Scientific Journal (special edition). 2,30-38.

Hassan, M. \& Sawalmeh, M. (2013). Error analysis of written English essays : The case of students of the preparatory year program in Saudi Arabia. English for Specific Purposes World. 14(40), 1-17.

Hyland, K. (2003). Second language writing. United Kingdom: Cambridge University Press.

Khan, A. B. \& Mansoor, H. (2016). The effectiveness of grammar translation method in teaching and learning of English language at intermediate level. International Journal of Institutional \& Industrial Research. 1(1), 22-25.

Kim, Y. \& Yoon, H. (2014). The use of L1 as a writing strategy in L2 writing tasks. GEMA Online Journal of Language Studies. 14(3), 33-50. https://doi.org/10.17576/GEMA2014-1403-03

Krish, P. \& Oh, C. M. (2020). A case study of L1 interference in speech acts among Chinese L2 students. 3L: Language, Linguistics, Literature. 26(1): 106-118. https://doi.org/10.17576/3L-2020-2601-08

Kumar, M. A., Dhanalakshmi, V., Soman, K. P. \& Sharmiladevi, V. (2014). Improving the performance of English-Tamil statistical machine translation system using source-side pre-processing. Proceeding of International Conference on Advances in Computer Science, AETACS, 2013.

Lado, R. (1957). Linguistics across cultures. Ann Arbor, MI: University of Michigan Press.

Listia, R. \& Febriyanti, E. R. (2020). EFL Learners' Problems in Using Tenses: An insight for grammar teaching. Indonesian Journal of English Teaching. 9(1), 86-95. https://doi.org/10.15642/ijet2.2020.9.1.86-95 
Maju Institute of Educational Development. (2020). 16 ${ }^{\text {th }}$ President's Achievers Award-UPSR 2017. Retrieved June 17, 2020, from https://mied.com.my/?p=1699.

Manan, N. A. A. \& Raslee, N. N. (2017). Describing the use of discourse markers by ESL learners in writing. International Journal of Advanced and Applied Sciences. 4(3), 101106. https://doi.org/10.21833/ijaas.2017.03.016

Maniam, M.( 2010). The influence of first language grammar (L1) on the English language (L2) writing of Tamil school students: A case study from Malaysia. Unpublished PhD Thesis, Language in India.

Maniam, M. \& Kesevan, H. V.(2016). Mother tongue syntactical influence in a ESL class. International Journal of Language and Linguistics. 3(3), 46-50.

Mayring, P. (2014). Qualitative content analysis: Theoretical foundation, basic procedures and software solution. Klagenfurt: Primary Publication.

Moe, M. M. \& Toe, T. (2020). Analysis of grammatical errors in the writings of undergraduate students in university. Journal of Computer Applications and Research. 1(1), 361-365.

Nazri, M. \& Azmi, L. (2013). Multilingualism and Personality Traits among Malay primary school students in vernacular schools. IOSR Journal Of Humanities And Social Science. $8(3), 24-31$.

Raman, S. (2007). Problems and challenges of learning through a second language: The case of teaching of Science and Mathematics in English in the Malaysian primary schools. Kajian Malaysia. 25(2), 29-54.

Ravishankar, N. \& Shriram, R. (2018). Grammar rule-based sentiment categorisation model for classification of Tamil tweets. International Journal of Intelligent Systems $\begin{array}{lll}\text { Technologies } & \text { and }\end{array}$ https://doi.org/10.1504/ijista.2018.10012884

Roslim, N. (2013). Prepositions and ESL learners: The Malaysian scenario. International Journal of Applied Linguistics \& English Literature. 3(1), 187-194. https://doi.org/10.7575/aiac.ijalel.v.3n.1p.187

Samuddin, K. M. \& Krish, P. (2018). English orthographic depth among Malay learners at a primary school. 3L: The Southeast Asian Journal of English Language Studies. 24(1), 56-68. http://doi.org/10.17576/3L-2018-2401-05

Sanmuganathan, K. (2014). Impact of L1 on ESL (English as a Second Language) writings of the undergraduates of University of Jaffna. Proceedings of Jaffna University International Research Conference (JUICE-2012).

Satariyan, A., Reynolds, B. \& Kember, D. (2018). The design and implementation of a short course, focusing on metacognition, to develop writing skills for university students for whom English is an additional language: An action research study. In Kember D., Corbett M. (Eds.), Structuring the Thesis (pp. 129-137). Springer Singapore. https://doi.org/10.1007/978-981-13-0511-5

Selvam, M., Natarajan, A. M., \& Thangarajan, R. (2009). Structural parsing of natural language text in Tamil language using dependency model. International Journal of Computer Processing of Languages. 22(3), 237-256. https://doi.org/10.1142/s1793840609002093

Singh, C. K. S., Jageer Singh, A. K., Abd Razak, N. Q. \& Ravinthar, T. (2017). Grammar errors made by ESL tertiary students in writing. English Language Teaching. 10(5), 16-27. https://doi.org/10.5539/elt.v10n5p16

Wang, W. \& Wen, Q. (2002). L1 use in the L2 composing process: An exploratory study of 16 Chinese EFL writers. Journal of Second Language Writing. 11(3), 225-246. https://doi.org/10.1016/S1060-3743(02)00084-X

Weinreich, U. (1953). Languages in contact: Findings and problems. New York: Linguistic Circle of New York. 


\section{ABOUT THE AUTHORS}

Prashana Nair Kumaran is an English teacher at a Primary School in Kuala Lumpur. She graduated with a Bachelor degree in Tamil language from Institute of Teacher Education and is currently pursuing an MPhil in English Language Studies at Universiti Kebangsaan Malaysia. Her research interests include language interference and cross-linguistic comparisons of language development.

Pramela Krish is an Associate Professor at the Centre for Research in Language and Linguistics, Faculty of Social Sciences and Humanities. 